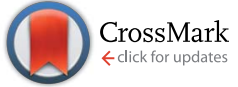

Cite this: RSC Adv., 2017, 7, 3934

Received 17th November 2016 Accepted 23rd December 2016

DOI: 10.1039/c6ra26923k

www.rsc.org/advances

\section{A novel negative thermal expansion material of $\mathrm{Zr}_{0.70} \mathrm{~V}_{1.33} \mathrm{Mo}_{0.67} \mathrm{O}_{6.73}$}

\author{
Mengdi Zhang, Yanchao Mao, Juan Guo, Wenjin Zhou, Mingju Chao, Niu Zhang, \\ Mengjie Yang, Xuhui Kong, Xiaoshuai Kong and Erjun Liang
}

A novel negative thermal expansion (NTE) material of $\mathrm{Zr}_{0.70} \mathrm{~V}_{1.33} \mathrm{Mo}_{0.67} \mathrm{O}_{6.73}$ was synthesized. Its microstructure, crystal structure and thermal expansion properties were studied in detail. Structure analysis shows that $\mathrm{Zr}_{0.70} \mathrm{~V}_{1.33} \mathrm{MO}_{0.67} \mathrm{O}_{6.73}$ possesses a cubic crystal structure with the space group $\mathrm{Pa} \overline{3}$ (no. 205) at room temperature (RT). The experimental results show that $\mathrm{Zr}_{0.70} \mathrm{~V}_{1.33} \mathrm{Mo}_{0.67} \mathrm{O}_{6.73}$ exhibits a stable isotropic negative thermal expansion property and maintains a cubic structure from 103 to $773 \mathrm{~K}$ without any phase transition. The average linear coefficients of thermal expansion (CTEs) are calculated to be $-3.75 \times 10^{-6} \mathrm{~K}^{-1}(163-673$ $\mathrm{K})$ and $-4.50 \times 10^{-6} \mathrm{~K}^{-1}(\mathrm{RT}-773 \mathrm{~K})$. The intrinsic linear CTEs are calculated to be $-3.84 \times 10^{-6} \mathrm{~K}^{-1}(103-$ $473 \mathrm{~K})$ and $-4.22 \times 10^{-6} \mathrm{~K}^{-1}(\mathrm{RT}-673 \mathrm{~K})$. And the phase transition temperature of $\mathrm{ZrV}_{2} \mathrm{O}_{7}$ has been reduced below RT, this may be attributed to the incorporation of the cubic $\mathrm{ZrMO}_{2} \mathrm{O}_{8}$ structure and partially occupied $\mathrm{Zr}$ atoms (4a). The NTE property of $\mathrm{Zr}_{0.70} \mathrm{~V}_{1.33} \mathrm{Mo}_{0.67} \mathrm{O}_{6.73}$ can be attributed to the quasi-rigid unit modes (QRUMs).

\section{Introduction}

Since Sleight et al. ${ }^{1}$ reported that the cubic $\mathrm{ZrW}_{2} \mathrm{O}_{8}$ exhibits isotropic negative thermal expansion (NTE) from 0.3 to $1050 \mathrm{~K}$ in 1995, the NTE materials have received extensive attention. NTE materials have potential application in the field of precise optics, aerospace, biomedical, integrated circuits and sensors due to their unique thermal expansion properties. ${ }^{2-4}$ However, the existing NTE materials still have many deficiencies from the perspective of application requirements. For instance, the typical NTE material $\mathrm{ZrW}_{2} \mathrm{O}_{8}$ is built of an open network of rigid $\mathrm{ZrO}_{6}$ octahedra and $\mathrm{WO}_{4}$ tetrahedra. It supports lower energy $(\sim 0.5$ $\mathrm{meV}$ ) phonon modes and has a metastable phase at room temperature. However, $\mathrm{ZrW}_{2} \mathrm{O}_{8}$ undergoes an order-disorder transition at $430 \mathrm{~K}\left(\alpha \rightarrow \beta\right.$, CTEs from $-8.8 \times 10^{-6} \mathrm{~K}^{-1}$ to $-4.9 \times$ $10^{-6} \mathrm{~K}^{-1}$ ) and it is easily to be decomposed above $770 \mathrm{~K}^{5-10} \mathrm{In}$ addition, its phase transition pressure is relatively low and will undergo a phase transition from $\alpha$ to $\gamma$ at 0.21 GPa (CTEs from $-8.8 \times 10^{-6} \mathrm{~K}^{-1}$ to $\left.-1.2 \times 10^{-6} \mathrm{~K}^{-1}\right)^{11}$ Similarly, the cubic $\mathrm{ZrMo}_{2} \mathrm{O}_{8}$ which is isostructural to $\mathrm{ZrW}_{2} \mathrm{O}_{8}$, has an average expansion coefficients of $-6.9 \times 10^{-6} \mathrm{~K}^{-1}(2-200 \mathrm{~K})$ and $-5.0 \times$ $10^{-6} \mathrm{~K}^{-1}(250-502 \mathrm{~K}) .^{12} \mathrm{~A}_{2} \mathrm{M}_{3} \mathrm{O}_{12}$ ( $\mathrm{A}$ is a rare earth or a transition metal, $\mathrm{M}$ is Mo or W) series NTE materials have the advantages of big CTEs, wide-temperature range and large chemical flexibility. However, its anisotropy and hydroscopicity are serious obstacles for achieving excellent NTE properties. ${ }^{4,13,14} \mathrm{ZrV}_{2} \mathrm{O}_{7}$ has a strong isotropic NTE characteristic from 375 to $1075 \mathrm{~K}$ (CTE $-7.1 \times$

Key Laboratory of Materials Physics of Ministry of Education, School of Physical Science and Engineering, Zhengzhou University, Zhengzhou 450052, China. E-mail: chaomingju@zzu.edu.cn; Fax: +8637167767758; Tel: +8637167767836
$10^{-6} \mathrm{~K}^{-1}$ ) and is stable at room temperature which is different from that of $\mathrm{ZrW}_{2} \mathrm{O}_{8}$. Nevertheless, it displays two first phase transitions at $350 \mathrm{~K}$ and $375 \mathrm{~K}$. It belongs to a $3 \times 3 \times 3$ superstructure below $350 \mathrm{~K}$ and transforms to $1 \times 1 \times 1$ cubic phase above $375 \mathrm{~K}$, meanwhile, it transforms from positive thermal expansion to NTE. In addition, $\mathrm{ZrV}_{2} \mathrm{O}_{7}$ undergoes a reversible phase transition at 1.38-1.58 GPa from $\alpha$ (cubic) to $\beta$ (pseudotetragonal). ${ }^{15-19}$ It should be highlighted that, this material will have an important application prospects if the phase transition temperature can be reduced to below room temperature.

From 1995 to 2001, Sleight et al. has done deep researches on $\mathrm{ZrV}_{2-x} \mathrm{P}_{x} \mathrm{O}_{7}$ series materials. ${ }^{15,17,21}$ In addition, Yamamura et al. has studied the phase transition temperature of $\mathrm{Zr}_{1-x} \mathrm{Hf}_{x} \mathrm{~V}_{2} \mathrm{O}_{7}{ }^{20}$ However, it's regrettable that the phase transition temperature hasn't been reduced to below room temperature successfully.

In this paper, we report a novel NTE material $\mathrm{Zr}_{0.70} \mathrm{~V}_{1.33^{-}}$ $\mathrm{Mo}_{0.67} \mathrm{O}_{6.73}$ for the first time, which exhibits a stable isotropic NTE property in a wide temperature range from 103 to $773 \mathrm{~K}$. Its crystal structure, microstructure and thermal expansion properties are studied in detail. The mechanism of the NTE property was also discussed. Its excellent NTE property integrated with the facile preparation method suggests potential applications of this novel material in many fields.

\section{Experimental procedures}

Analytica-grade $\mathrm{ZrO}_{2}, \mathrm{~V}_{2} \mathrm{O}_{5}$ and $\mathrm{MoO}_{3}$ powders were used as starting materials and mixed according to the molar ratio of $0.70: 1.40: 0.70$ as eqn (1).

$0.70 \mathrm{ZrO}_{2}+1.33 \mathrm{~V}_{2} \mathrm{O}_{5}+0.67 \mathrm{MoO}_{3}=\mathrm{Zr}_{0.70} \mathrm{~V}_{1.33} \mathrm{Mo}_{0.67} \mathrm{O}_{6.73}$ 
The excess $\mathrm{V}_{2} \mathrm{O}_{5}$ and $\mathrm{MoO}_{3}$ is to compensate for their evaporation during heating. Raw materials were thoroughly mixed and ground for $2 \mathrm{~h}$ with absolute ethyl alcohol in an agate mortar. The homogenized raw materials were pressed into cylindrical pellets with diameter of $5 \mathrm{~mm}$ and thickness of 3-5 $\mathrm{mm}$ by $769 \mathrm{YP}-15 \mathrm{~A}$ powder tableting machine in $8 \mathrm{MPa}$ and dwelled $5 \mathrm{~min}$. The pellets were put into a tubular furnace preheated to sintering temperature at $953 \mathrm{~K}$ and maintained for $4 \mathrm{~h}$ before quenched, then dried at $473 \mathrm{~K}$ for $1 \mathrm{~h}$. To get more uniform sample, the process of ground, press and sinter was performed for a secondary round according to the process described above. Final sample was obtained after annealed at $673 \mathrm{~K}$.

A D8 ADVANCE X-ray diffractometer (Germany Bruker) was used for room, high and low temperature XRD measurements; a Quanta250 scanning electron micrograph (SEM, USA FEI) and a APOLLO XP energy dispersive spectroscopy (EDS, USA EDAX) were used to analysis microstructure and chemical of sample; a ESCALAB 250Xi X-ray photoelectron spectroscopy (XPS, Germany Thermo Fisher) was used to analyze the composition of the samples and states of elements; a STA 449F3 simultaneous thermal analyzer (Germany Netzsch, in the temperature range of 300-873 $\mathrm{K}$ with heating and cooling rates of $10 \mathrm{~K} \mathrm{~min}^{-1}$ ) was used to differential scanning calorimetry (DSC) and thermogravimetric measurements (TG); a LabRAM HR Evolution Raman spectrometer (France HORIBA Jobin Yvon S.A.S.) was used to measure room temperature and temperature-dependent Raman spectral; a LINSEIS DIL L75 dilatometer (Germany LINSEIS, in the temperature range of RT-773 K with heating rate of $5 \mathrm{~K} \mathrm{~min}^{-1}$ ) and a LINSEIS DIL L76 dilatometer (Germany LINSEIS, in the temperature range of 163-673 $\mathrm{K}$ with heating rate of $5 \mathrm{~K} \mathrm{~min}^{-1}$ ) were used to measure the relative length changes depended temperature.

\section{Results and discussion}

\subsection{Microstructure}

Fig. 1a shows the SEM image of the sample. It can be seen that the ceramic sample is composed of irregular particles with different sizes and smooth surface. The average particle sizes are approximately 1-6 $\mu \mathrm{m}$. Fig. 1b shows the EDS spectrum corresponding to Fig. 1a. The EDS analysis of the grains presents primary elements of $\mathrm{Zr}, \mathrm{V}$, Mo and $\mathrm{O}$.

To further confirm the composition of sample, we also performed XPS analyses. Fig. 2a shows the survey scan XPS spectrum of sample, and $\mathrm{Zr}, \mathrm{V}$, Mo and $\mathrm{O}$ signals can be clearly observed. The Zr 3d, V 2p, Mo 3d and O 1s XPS spectra are shown in Fig. 2b-e. The Zr 3d, V 2p and Mo 3d peak values are in agreement with the existing reports, ${ }^{22-24}$ confirming the state of $\mathrm{Zr}^{4+}, \mathrm{V}^{5+}$ and $\mathrm{Mo}^{6+}$ in $\mathrm{Zr}_{0.70} \mathrm{~V}_{1.33} \mathrm{Mo}_{0.67} \mathrm{O}_{6.73}$. We also calculated the atomic ratio of $\mathrm{Zr}, \mathrm{V}, \mathrm{Mo}$ and $\mathrm{O}$ by the relative sensitivity factor (RSF) method based on eqn (2) and (3).

$$
C_{\mathrm{x}}=\frac{n_{\mathrm{x}}}{\sum_{i} n_{i}}=\frac{\frac{I_{\mathrm{x}}}{S_{\mathrm{x}}}}{\sum_{i} \frac{I_{i}}{S_{i}}}
$$

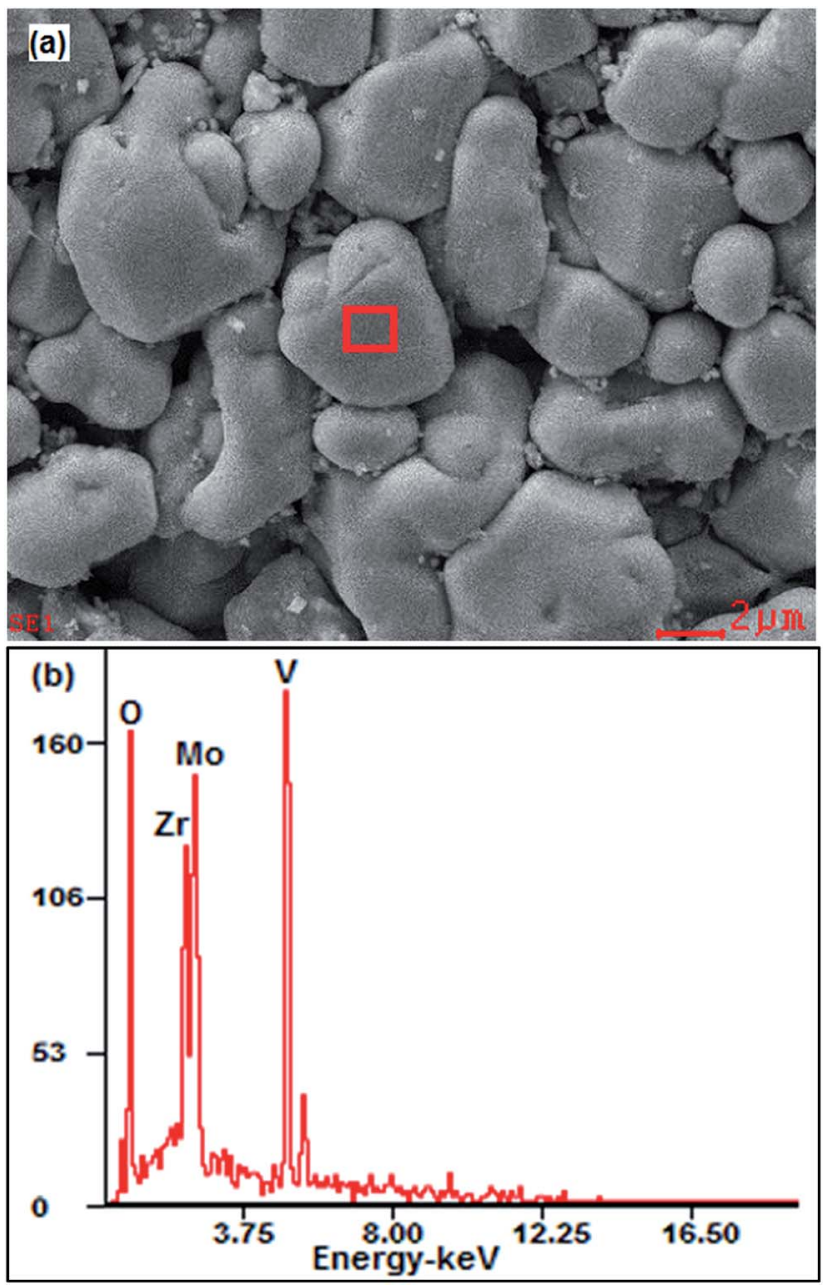

Fig. 1 SEM image and EDS spectrum. (a) SEM image of sample; (b) EDS spectrum corresponding to (a).

$$
\frac{n_{i}}{n_{j}}=\frac{\frac{I_{i}}{S_{i}}}{\frac{I_{j}}{S_{j}}}
$$

where $C_{\mathrm{x}}, I_{\mathrm{x}}, S_{\mathrm{x}}$ and $n_{\mathrm{x}}$ denote the relative content, characteristic spectra integral area, RSF and content of $x$ element, respectively. The results were show in Table 1. It can be clearly seen that the atomic ratio of $\mathrm{Zr}, \mathrm{V}, \mathrm{Mo}$ and $\mathrm{O}$ are about $0.7: 1.33: 0.67: 6.73$, which in good agreement with the molar ratio of starting materials.

\subsection{Crystal structure}

The crystal structure is refined by Rietveld analysis with software of Fullprof. Fig. 3 exhibit the Rietveld analysis for the RT XRD pattern. It must be highlighted that the refinement has reference the result of Sahoo et al. about $\mathrm{ZrV}_{2-x} \mathrm{Mo}_{x} \mathrm{O}_{7+\delta}{ }^{25}$ The analysis shows that the sample adopts a cubic crystal structure with space group of $P a \overline{3}$ (no. 205). The cell lattice parameters and volume are calculated to be $a=b=c=8.93063 \AA, V=$ $712.27316 \AA^{3}$, respectively, with the acceptable values of, $R_{\mathrm{p}}=$ $17.6 \%, R_{\mathrm{wp}}=14.4 \%$ and $R_{\exp }=11.17 \%$. 

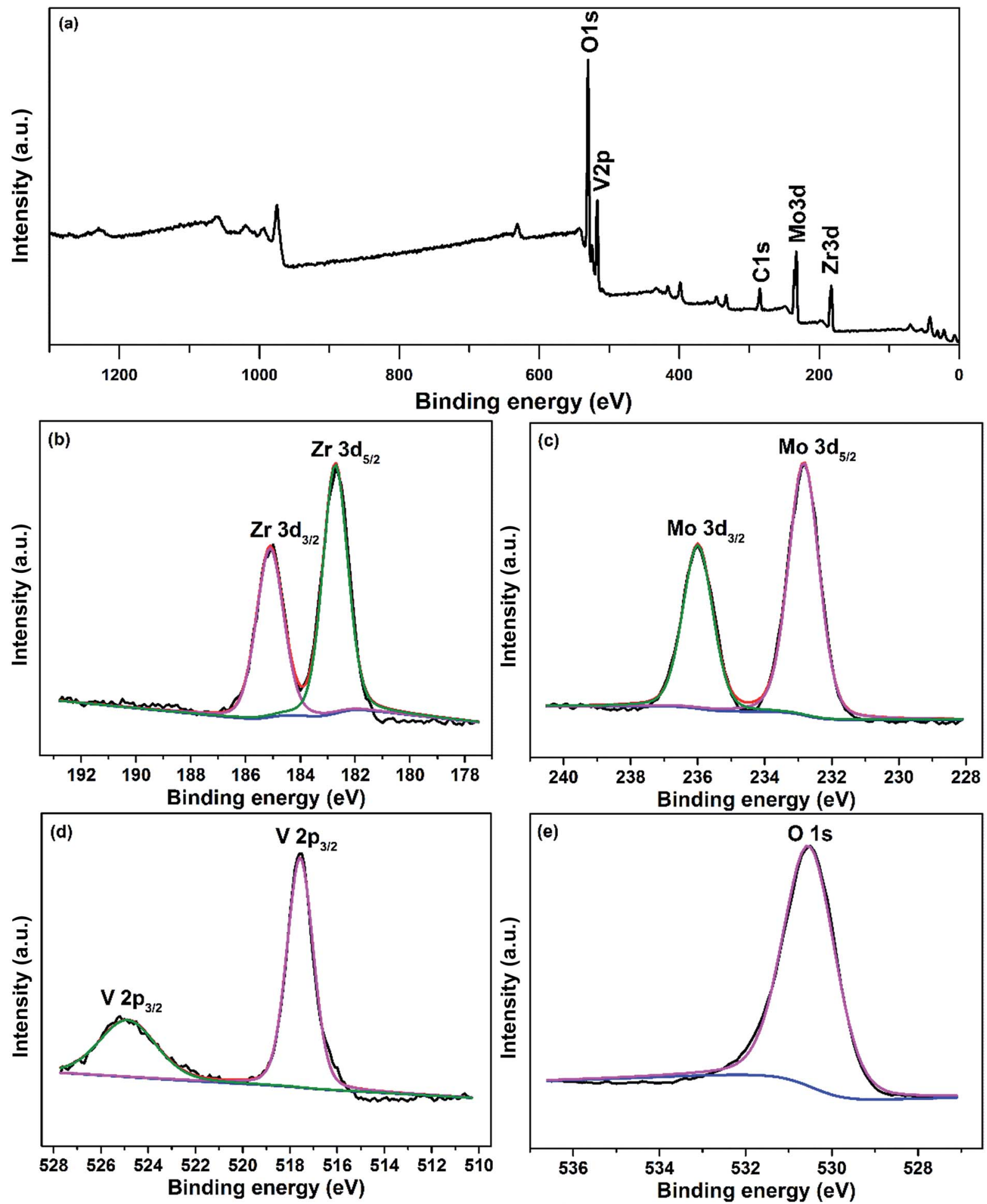

Fig. 2 The XPS spectra of sample: (a) the survey scan XPS spectrum; (b) Zr 3d; (c) V 2p; (d) Mo 3d; (e) O 1s.

Fig. 4a presents the schematic diagram of $\mathrm{Zr}_{0.70} \mathrm{~V}_{1.33} \mathrm{Mo}_{0.67^{-}}$ $\mathrm{O}_{6.73}$ building block depending on the XRD refinement result. The crystal structures are characterized by linkages of corner shared $\mathrm{VO}_{4}$ or $\mathrm{MoO}_{4}$ tetrahedra and $\mathrm{ZrO}_{6}$ octahedra. The $\mathrm{ZrO}_{6}$ octahedra share all the oxygen atoms with the adjacent $\mathrm{VO}_{4}$ or $\mathrm{MoO}_{4}$ tetrahedra. On the other hand, the two $\mathrm{VO}_{4}$ tetrahedra share an oxygen atom and make a $\mathrm{V}_{2} \mathrm{O}_{7}$ group. Each $\mathrm{MoO}_{4}$ tetrahedron, however, share only three of its four oxygens with the neighboring $\mathrm{ZrO}_{6}$ octahedra, and consequently, has one unshared vertex. The $\mathrm{ZrV}_{2} \mathrm{O}_{7}$ crystallizes in the centrosymmetric $P a \overline{3}$ (no. 205), ${ }^{15}$ however, it undergoes a phase transformation from the space group $P 2_{1} 3$ to $P a \overline{3}$ at $483 \mathrm{~K}$. Whereas cubic 
Table 1 The integration and atomic ratio results of $\mathrm{Zr} 3 d, \vee 2 p$, Mo $3 d$ and $\mathrm{O} 1 \mathrm{~s}$

\begin{tabular}{lrlrl}
\hline Element & \multicolumn{1}{c}{ RSF } & Area & Area/RSF & $\begin{array}{l}\text { Atomic } \\
\text { ratio }\end{array}$ \\
\hline Zr 3d & 9.032 & 20893.893 & 2303.354 & 0.700 \\
V 2p & 9.280 & 40464.230 & 4360.370 & 1.325 \\
Mo 3d & 11.008 & 24716.019 & 2249.366 & 0.684 \\
O 1s & 2.881 & 64939.260 & 22540.528 & 6.850 \\
\hline
\end{tabular}

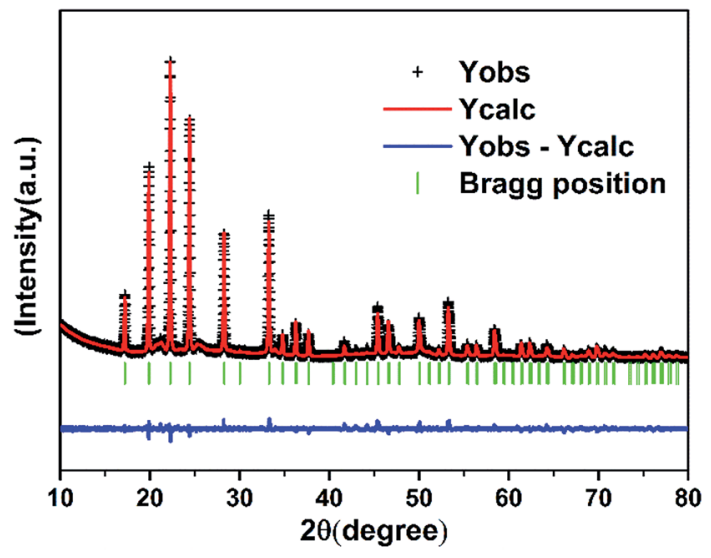

Fig. 3 XRD pattern of the sample at RT and the result of Rietveld analysis.

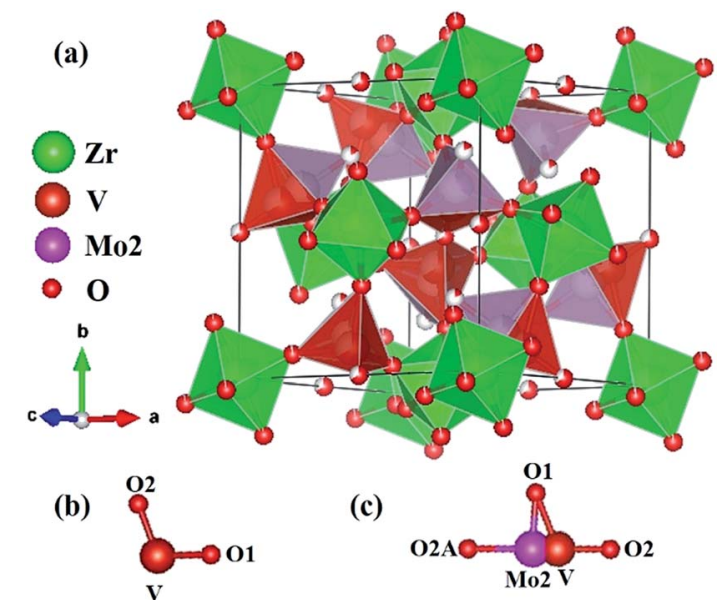

Fig. 4 Schematic diagram of $\mathrm{Zr}_{0.70} \mathrm{~V}_{1.33} \mathrm{Mo}_{0.67} \mathrm{O}_{6.73}$. (a) Polyhedral representation of $\mathrm{Zr}_{0.70} \mathrm{~V}_{1.33} \mathrm{Mo}_{0.67} \mathrm{O}_{6.73}$; (b) asymmetric unit of $\mathrm{ZrV}_{2} \mathrm{O}_{7}$; (c) asymmetric unit of $\mathrm{Zr}_{0.70} \mathrm{~V}_{1.33} \mathrm{Mo}_{0.67} \mathrm{O}_{6.73}$.

$\mathrm{ZrW}_{2} \mathrm{O}_{8}$ crystallize in the noncentrosymmetric space group $P 2_{1} 3$ (no. 198). ${ }^{8}$ As cubic $\mathrm{ZrW}_{2} \mathrm{O}_{8}$ is isostructural to cubic $\mathrm{ZrMo}_{2} \mathrm{O}_{8}$, we will compare the $\mathrm{Zr}_{0.70} \mathrm{~V}_{1.33} \mathrm{Mo}_{0.67} \mathrm{O}_{6.73}$ with $\mathrm{HT}-\mathrm{ZrW}_{2} \mathrm{O}_{8}$. Table 2 provides the atomic coordinates of the current compound of $\mathrm{Zr}_{0.70} \mathrm{~V}_{1.33} \mathrm{Mo}_{0.67} \mathrm{O}_{6.73}, \mathrm{ZrV}_{2} \mathrm{O}_{7}$ and $\mathrm{HT}-\mathrm{ZrW}_{2} \mathrm{O}_{8}$. A comparison of the asymmetric unit of $\mathrm{Zr}_{0.70} \mathrm{~V}_{1.33} \mathrm{Mo}_{0.67} \mathrm{O}_{6.73}$ with $\mathrm{ZrV}_{2} \mathrm{O}_{7}$ is shown in Fig. $4 \mathrm{~b}$ and c. It is clear that the formula derived from the $\mathrm{XRD}$ refinement result is $\mathrm{Zr}_{0.70} \mathrm{~V}_{1.33} \mathrm{Mo}_{0.67} \mathrm{O}_{6.73}$ and the structure of $\mathrm{Zr}_{0.70} \mathrm{~V}_{1.33} \mathrm{Mo}_{0.67} \mathrm{O}_{6.73}$ is a hybrid of $\mathrm{ZrV}_{2} \mathrm{O}_{7}$ and cubic $\mathrm{ZrMo}_{2} \mathrm{O}_{8}$. The incorporation of cubic $\mathrm{ZrMo}_{2} \mathrm{O}_{8}$ structure and partially occupied $\mathrm{Zr}$ atoms (4a) maybe the main reasons of the phase transition temperature decrease. And the NTE in $\mathrm{Zr}_{0.70} \mathrm{~V}_{1.33} \mathrm{Mo}_{0.67} \mathrm{O}_{6.73}$ can be mainly attributed to the QRUMs, which will be discussed later.

\subsection{Thermal expansion properties}

Fig. 5 shows the relative length (\%) change of $\mathrm{Zr}_{0.70} \mathrm{~V}_{1.33^{-}}$ $\mathrm{Mo}_{0.67} \mathrm{O}_{6.73}$ ceramic with temperature measured by hightemperature dilatometer (RT-773 K) and low-temperature dilatometer (163-673 K), respectively. It shows that $\mathrm{Zr}_{0.70} \mathrm{~V}_{1.33^{-}}$ $\mathrm{Mo}_{0.67} \mathrm{O}_{6.73}$ ceramic exhibits the NTE from 163 to $773 \mathrm{~K}$, and the average linear CTEs are calculated to be $-3.75 \times 10^{-6} \mathrm{~K}^{-1}$ $(163-673 \mathrm{~K})$ and $-4.50 \times 10^{-6} \mathrm{~K}^{-1}$ (RT-773 K).

Fig. $6 \mathrm{a}$ and $\mathrm{c}$ show the low and high temperature XRD patterns of $\mathrm{Zr}_{0.70} \mathrm{~V}_{1.33} \mathrm{Mo}_{0.67} \mathrm{O}_{6.73}$ ceramic. The XRD patterns remain unchanged from 103 to $473 \mathrm{~K}$ and from RT to $673 \mathrm{~K}$ except successful shifts of the diffraction peaks to higher angles, suggesting that $\mathrm{Zr}_{0.70} \mathrm{~V}_{1.33} \mathrm{Mo}_{0.67} \mathrm{O}_{6.73}$ keeps the cubic structure from 103 to $673 \mathrm{~K}$ without phase transitions. The successive shifts of the diffraction peaks to higher angles reveals a contraction in lattice constants with increasing temperature in complete agreement with the result of Fig. 5. Fig. $6 \mathrm{~b}$ and $\mathrm{d}$ exhibit the changes of the lattice constants along $a, b, c$ axes $(a=b=c)$ and lattice volume $V$ with temperature which is calculated by PowderX. The intrinsic linear CTEs of $a$-, $b$-, and $c$-axes are calculated to be $\alpha_{a}=\alpha_{b}=\alpha_{c}=-3.84 \times$ $10^{-6} \mathrm{~K}^{-1}(103-463 \mathrm{~K})$ and $\alpha_{a}=\alpha_{b}=\alpha_{c}=-4.22 \times 10^{-6} \mathrm{~K}^{-1}$ (RT-

Table 2 Atomic coordinates of $\mathrm{Zr}_{0.70} \mathrm{~V}_{1.33} \mathrm{Mo}_{0.67} \mathrm{O}_{6.73}, \mathrm{ZrV}_{2} \mathrm{O}_{7}$ and $\mathrm{HT}$ $\mathrm{ZrW}_{2} \mathrm{O}_{8}$

\begin{tabular}{llll}
\hline & $\mathrm{Zr}_{0.70} \mathrm{~V}_{1.33} \mathrm{Mo}_{0.67} \mathrm{O}_{6.73}$ & $\begin{array}{l}\mathrm{ZrV}_{2} \mathrm{O}_{7} \\
(\mathrm{ref} .15)\end{array}$ & $\begin{array}{l}\mathrm{HT}-\mathrm{ZrW}_{2} \mathrm{O}_{8} \\
\text { (ref. 8) }\end{array}$ \\
\hline $\begin{array}{llll}\mathrm{Atom} \\
x=y=z\end{array}$ & $\mathrm{Zr}(4 \mathrm{a})$ & $\mathrm{Zr}(4 \mathrm{a})$ & $\mathrm{Zr}(4 \mathrm{a})$ \\
Occupancy & 0.7 & 1 & 0 \\
\hline Atom & $\mathrm{V}(8 \mathrm{c})$ & $\mathrm{V}(8 \mathrm{c})$ & $\mathrm{W} 1(8 \mathrm{c})$ \\
$x=y=z$ & 0.40072 & 0.38174 & 0.33945 \\
Occupancy & 0.66667 & 1 & 0.5 \\
\hline Atom & $\mathrm{Mo2}(8 \mathrm{c})$ & & $\mathrm{W} 2(8 \mathrm{c})$ \\
$x=y=z$ & 0.34932 & & 0.60355 \\
Occupancy & 0.33333 & & 0.5 \\
\hline Atom & $\mathrm{O} 2(4 \mathrm{~b})$ & $\mathrm{O} 2(4 \mathrm{~b})$ & $\mathrm{O} 3(8 \mathrm{c})$ \\
$x=y=z$ & 0.5 & 0.5 & 0.50550 \\
Occupancy & 0.66667 & 1 & 0.5 \\
\hline Atom & $\mathrm{O} 2 \mathrm{~A}(8 \mathrm{c})$ & & $\mathrm{O} 4(8 \mathrm{c})$ \\
$x=y=z$ & 0.23221 & & 0.23224 \\
Occupancy & 0.16667 & & 0.5 \\
\hline Atom & $\mathrm{O} 1(24 \mathrm{~d})$ & & $\mathrm{O} 1(24 \mathrm{~d})$ \\
$x$ & 0.45206 & $0.051(24 \mathrm{~d})$ & -0.20893 \\
$y$ & 0.18844 & 0.43634 & -0.06713 \\
$z$ & 0.41926 & 0.40730 & 1 \\
Occupancy & 0.95556 & &
\end{tabular}




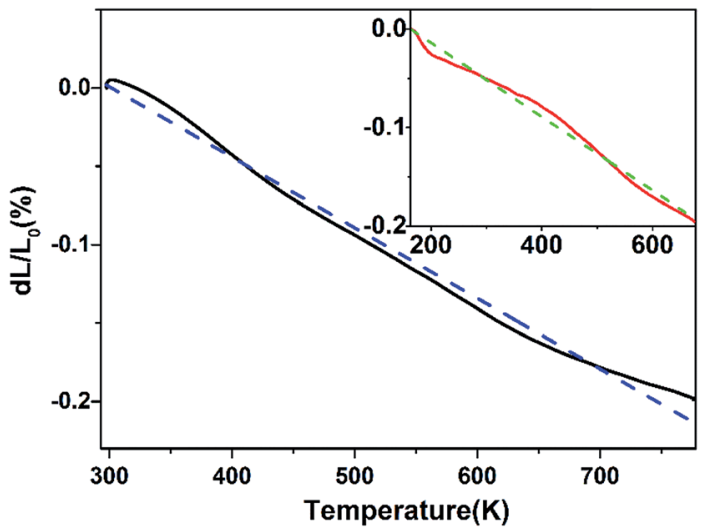

Fig. 5 Relative length (\%) changes of the $\mathrm{Zr}_{0.70} \mathrm{~V}_{1.33} \mathrm{Mo}_{0.67} \mathrm{O}_{6.73}$ ceramic with temperature from RT to $773 \mathrm{~K}$ and from 163 to $673 \mathrm{~K}$ (inset). The dotted lines are linear fits to the experimental data.

$673 \mathrm{~K})$. The volume CTEs are calculated to be $\alpha_{V}=-11.5 \times 10^{-6}$ $\mathrm{K}^{-1}(103-463 \mathrm{~K})$ and $\alpha_{V}=-12.7 \times 10^{-6} \mathrm{~K}^{-1}(\mathrm{RT}-673 \mathrm{~K})$, which agree well with the results measured by dilatometry (see Fig. 5).

Fig. 7 shows the DSC and thermogravimetric plots of the $\mathrm{Zr}_{0.70} \mathrm{~V}_{1.33} \mathrm{Mo}_{0.67} \mathrm{O}_{6.73}$. The mass increase and dip in DSC before $335 \mathrm{~K}$ are an instrumental artifact and thermal drift. Neither evident endothermic/exothermic peaks nor obvious weight loss from RT to $873 \mathrm{~K}$ appear, confirming that $\mathrm{Zr}_{0.70} \mathrm{~V}_{1.33} \mathrm{Mo}_{0.67} \mathrm{O}_{6.73}$ possesses perfect thermal stability and does not exhibit phase transition from RT to $873 \mathrm{~K}$.

\subsection{Thermal shrink mechanism discussed}

Fig. 8a shows the RT Raman spectrum of $\mathrm{Zr}_{0.70} \mathrm{~V}_{1.33} \mathrm{Mo}_{0.67} \mathrm{O}_{6.73}$. The Raman modes in the ranges $310-400 \mathrm{~cm}^{-1}, 480-550 \mathrm{~cm}^{-1}$, $700-850 \mathrm{~cm}^{-1}$ and $850-1050 \mathrm{~cm}^{-1}$ are identified as symmetric bending $\left(\nu_{2}\right)$, asymmetric bending $\left(\nu_{4}\right)$, asymmetric stretching $\left(\nu_{3}\right)$ and symmetric stretching $\left(\nu_{1}\right)$ modes of the $\mathrm{MoO}_{4}$ and $\mathrm{VO}_{4}$ tetrahedra, respectively. And those peaks below $300 \mathrm{~cm}^{-1}$ are vibration of $\mathrm{Zr}$ atomic and translational and librational modes of $\mathrm{MoO}_{4}$ and $\mathrm{VO}_{4}$ tetrahedra. ${ }^{\mathbf{1 4 , 1 9 , 2 6 , 2 7}}$ Fig. $8 \mathrm{~b}$ shows the temperaturedependent Raman spectra of $\mathrm{ZrMoV}_{2} \mathrm{O}_{10}$ from 4 to $464 \mathrm{~K}$. It reveals that there are no distinct appear or disappear of Raman peaks. The Raman shifts occur successively redshift from 4 to 24 $\mathrm{K}$ and blue shift from 24 to $54 \mathrm{~K}$, so it can be speculated that the temperature range of $24-54 \mathrm{~K}$ is the transition of superstructure. ${ }^{15,16}$ Meanwhile, the Raman shifts occur redshift from 54 to $464 \mathrm{~K}$ without changing the amount of Raman peaks, suggesting that $\mathrm{Zr}_{0.70} \mathrm{~V}_{1.33} \mathrm{Mo}_{0.67} \mathrm{O}_{6.73}$ keeps the cubic structure from 54 to $464 \mathrm{~K}$ without phase transitions. It can be also confirmed by the result of DSC (Fig. 7). The rotations of $\mathrm{MoO}_{4}$ and $\mathrm{VO}_{4}$ tetrahedra with increasing temperature result in the change of symmetric
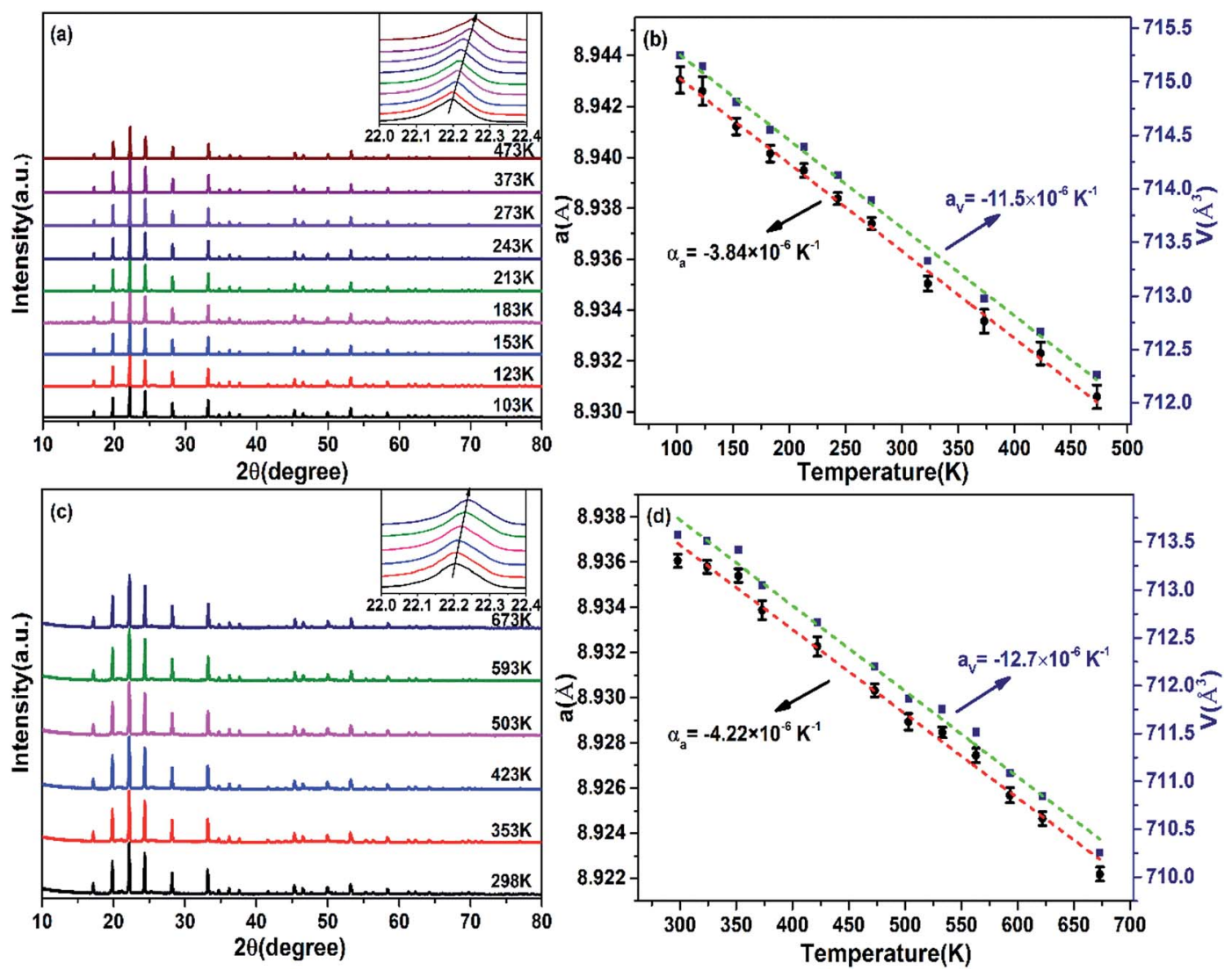

Fig. 6 Temperature dependent XRD. (a) Low temperature XRD patterns of $Z_{0.70} V_{1.33} M_{0.67} \mathrm{O}_{6.73}$ (the inset on right top is the enlarged view of the main peak between $22.0^{\circ}$ and $22.4^{\circ}$ ); (b) change in lattice constant and cell volume of $\mathrm{Zr}_{0.70} \mathrm{~V}_{1.33} \mathrm{Mo}_{0.67} \mathrm{O}_{6.73}$ of low temperature $\mathrm{XRD}$; (c) high temperature XRD patterns of $\mathrm{Zr}_{0.70} \mathrm{~V}_{1.33} \mathrm{Mo}_{0.67} \mathrm{O}_{6.73}$ (the inset on right top is the enlarged view of the main peak between $22.0^{\circ}$ and $22.4^{\circ}$ ); $(\mathrm{d}$ ) change in lattice constant and cell volume of $\mathrm{Zr}_{0.70} \mathrm{~V}_{1.33} \mathrm{Mo}_{0.67} \mathrm{O}_{6.73}$ of high temperature XRD. 


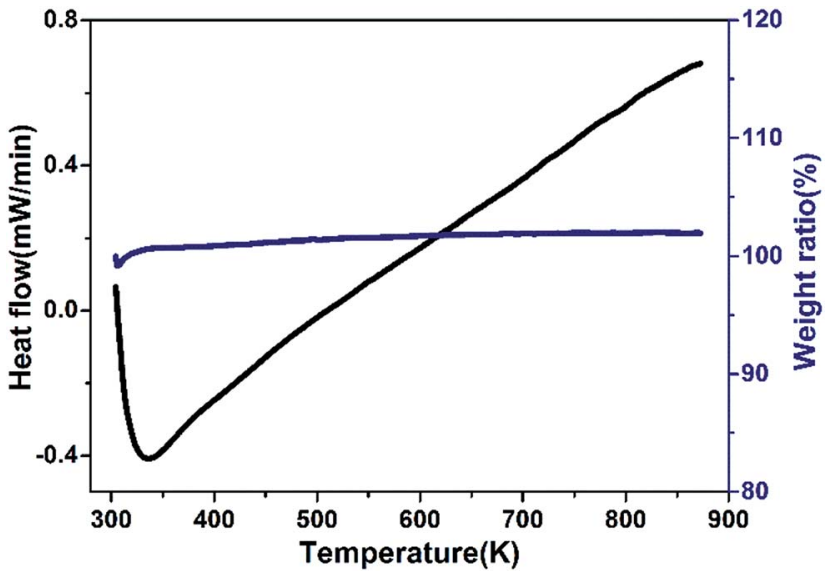

Fig. 7 Typical DSC and thermogravimetric plots for $\mathrm{Zr}_{0.70} \mathrm{~V}_{1.33} \mathrm{Mo}_{0.67} \mathrm{O}_{6.73}$.
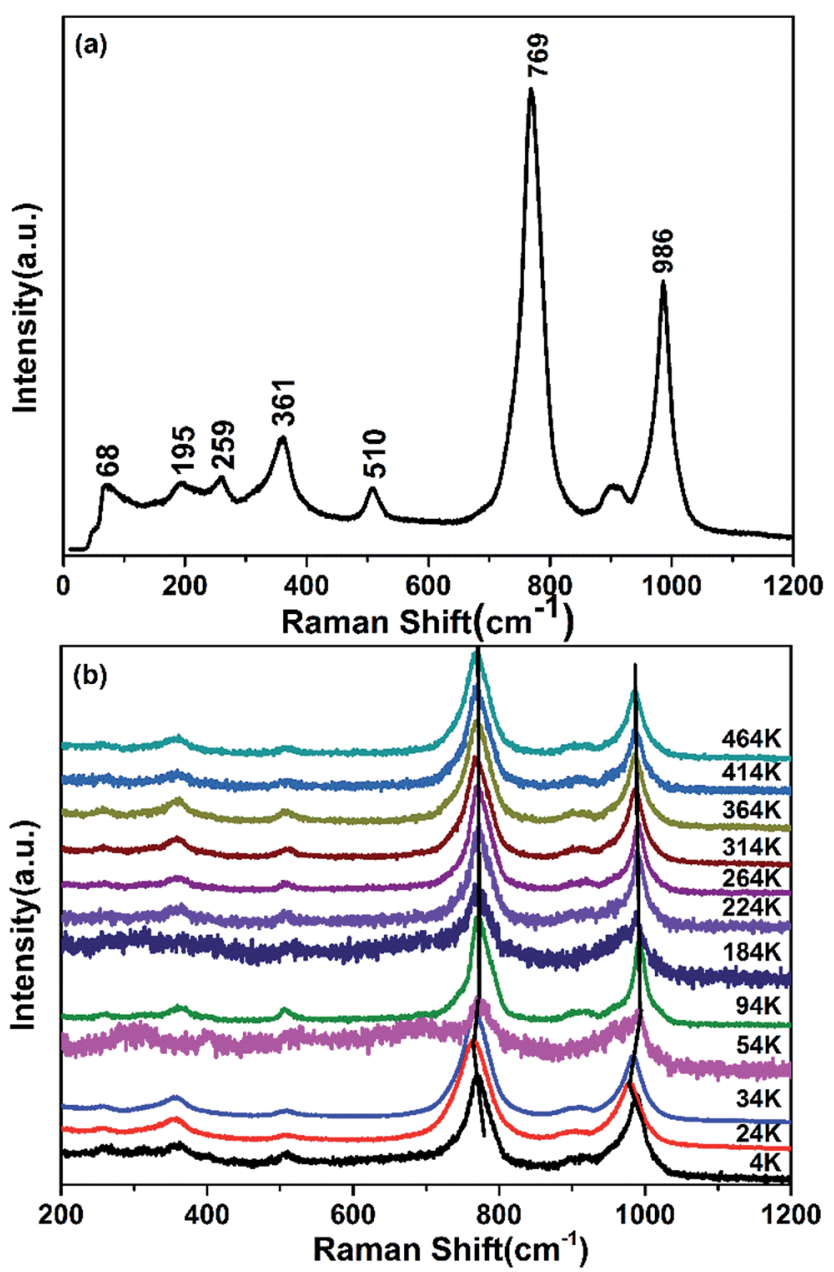

Fig. 8 Raman spectra. (a) Room temperature Raman spectrum of $\mathrm{Zr}_{0.70} \mathrm{~V}_{1.33} \mathrm{Mo}_{0.67} \mathrm{O}_{6.73}$; (b) low temperature Raman spectra of $\mathrm{Zr}_{0.70^{-}}$ $\mathrm{V}_{1.33} \mathrm{MO}_{0.67} \mathrm{O}_{6.73}$ from 4 to $464 \mathrm{~K}$.

bending $\left(\nu_{2}\right)$, asymmetric bending $\left(\nu_{4}\right)$, asymmetric stretching $\left(\nu_{3}\right)$ and symmetric stretching $\left(\nu_{1}\right)$ vibrational modes, which is the main reason for the redshift of Raman bands.
From the results of XRD refinement and temperature dependent Raman spectra, we deduced that $\mathrm{Zr}_{0.70} \mathrm{~V}_{1.33} \mathrm{Mo}_{0.67}$ $\mathrm{O}_{6.73}$ belongs to a $3 \times 3 \times 3$ superstructure below $24 \mathrm{~K}$ then starts to transition from $3 \times 3 \times 3$ superstructure to $1 \times 1 \times 1$ cubic phase and completely transition to $1 \times 1 \times 1$ cubic phase above $54 \mathrm{~K}$. It exhibits stable NTE property above $54 \mathrm{~K}$. Considered the similarities of structure and properties between $\mathrm{Zr}_{0.7} \mathrm{~V}_{1.4} \mathrm{Mo}_{0.7} \mathrm{O}_{7}$ and $\mathrm{ZrV}_{2} \mathrm{O}_{7},{ }^{15,17,27}$ we regard $\mathrm{MoO}_{4}$, $\mathrm{VO}_{4}$ tetrahedra and $\mathrm{ZrO}_{6}$ octahedra in $\mathrm{Zr}_{0.70} \mathrm{~V}_{1.33} \mathrm{Mo}_{0.67} \mathrm{O}_{6.73}$ crystal as quasi-rigid, when the temperature is higher than 54 $\mathrm{K}$, the polyhedra vibrate as the temperature increasing. The tilts and rotations of $\mathrm{MoO}_{4}$ and $\mathrm{VO}_{4}$ tetrahedra, will necessarily drag the $\mathrm{ZrO}_{6}$ octahedra along with it, and pull the rest of the structure in, giving a volume reduction. Since this tilts and rotations, and hence volume reduction, will be larger at higher temperature, there will be a NTE property. It is of interest to note that in $\mathrm{ZrV}_{2} \mathrm{O}_{7}$, the negative thermal expansion begins at $375 \mathrm{~K}$. Nevertheless, in $\mathrm{Zr}_{0.70} \mathrm{~V}_{1.33} \mathrm{Mo}_{0.67} \mathrm{O}_{6.73}$, it begins at $54 \mathrm{~K}$. This indicates that the phase transition temperature has been reduced to $54 \mathrm{~K}$. According to the preceding crystal structure analysis in 3.3 and the NTE property of cubic $\mathrm{ZrMo}_{2} \mathrm{O}_{8},{ }^{8,15}$ we deduced that it may be attributed to the incorporation of cubic $\mathrm{ZrMo}_{2} \mathrm{O}_{8}$ structure and partially occupied $\mathrm{Zr}$ atoms (4a).

\section{Conclusion}

In summary, we developed a novel NTE material $\mathrm{Zr}_{0.70} \mathrm{~V}_{1.33^{-}}$ $\mathrm{Mo}_{0.67} \mathrm{O}_{6.73}$, which possesses excellent stable isotropic NTE property and keeps cubic crystal structure over a wide temperature range from 103 to $773 \mathrm{~K}$. Structure analysis shows that $\mathrm{Zr}_{0.70} \mathrm{~V}_{1.33} \mathrm{Mo}_{0.67} \mathrm{O}_{6.73}$ has a cubic structure with the space group $P a \overline{3}$ (no. 205). The average linear CTEs are calculated to be $-3.75 \times 10^{-6} \mathrm{~K}^{-1}(163-673 \mathrm{~K})$ and $-4.50 \times 10^{-6} \mathrm{~K}^{-1}(\mathrm{RT}-773$ $\mathrm{K})$. The intrinsic linear CTEs are calculated to be $-3.84 \times 10^{-6}$ $\mathrm{K}^{-1}(103-473 \mathrm{~K})$ and $-4.22 \times 10^{-6} \mathrm{~K}^{-1}$ (RT-673 K). $\mathrm{Zr}_{0.70} \mathrm{~V}_{1.33^{-}}$ $\mathrm{Mo}_{0.67} \mathrm{O}_{6.73}$ belongs to a $3 \times 3 \times 3$ superstructure below $24 \mathrm{~K}$ and $1 \times 1 \times 1$ cubic phase above $54 \mathrm{~K}$ while it exhibits the stable isotropic NTE property. The NTE property can be attributed to the QRUMs. And the phase transition temperature of $\mathrm{ZrV}_{2} \mathrm{O}_{7}$ has been reduced below RT, this may be attributed to the incorporation of $\mathrm{ZrMo}_{2} \mathrm{O}_{8}$ structure and partially occupied $\mathrm{Zr}$ atoms (4a). The excellent NTE property integrated with the facile preparation method implies potential application of $\mathrm{Zr}_{0.70^{-}}$ $\mathrm{V}_{1.33} \mathrm{Mo}_{0.67} \mathrm{O}_{6.73}$. This work could open up new opportunities for developing NTE materials.

\section{Acknowledgements}

The authors acknowledge the financial support given by the National Natural Science Foundation of China (11574276, 51503185), and the Key Natural Science Project of Henan Province (142102210073), China Postdoctoral Science Foundation (2015M580636, 2016T90637) and the Startup Research Fund of Zhengzhou University (1512317010). 


\section{References}

1 T. A. Mary, J. S. O. Evans, T. Vogt and A. W. Sleight, Science, 1996, 272, 90-92.

2 Y. G. Cheng, Y. Liang, X. H. Ge, X. S. Liu, B. H. Yuan, J. Guo, M. J. Chao and E. J. Liang, RSC Adv., 2016, 6, 53657-53661.

3 C. Zhou, Q. Zhang, S. Y. Liu, T. Zhou, J. R. Jokisaari and G. H. Wu, J. Alloys Compd., 2016, 670, 182-187.

4 X. H. Ge, Y. C. Mao, X. S. Liu, Y. G. Cheng, B. H. Yuan, M. J. Chao and E. J. Liang, Sci. Rep., 2016, 6, 24832.

5 G. Ernst, C. Broholm, G. R. Kowach and A. P. Ramirez, Nature, 1998, 396, 147-149.

6 R. Mittal and S. L. Chaplot, Phys. Rev. B: Condens. Matter Mater. Phys., 1999, 60, 7234.

7 D. Cao, F. Bridges, G. R. Kowach and A. P. Ramirez, Phys. Rev. Lett., 2002, 89, 215902.

8 J. S. O. Evans, T. A. Mary, T. Vogt, M. A. Subramanian and A. W. Sleight, Chem. Mater., 1996, 8, 2809-2823.

9 J. S. O. Evans, Z. Hu, J. D. Jorgensen, D. N. Argyriou, S. Short and A. W. Sleight, Science, 1997, 275, 61-65.

10 Y. Yamamura, N. Nakajima and T. Tsuji, Solid State Commun., 2000, 114, 453-455.

11 C. A. Perottoni and J. A. H. Da Jornada, Science, 1998, 280, 886-889.

12 S. Allen and J. S. O. Evans, Phys. Rev. B: Condens. Matter Mater. Phys., 2003, 68, 134101.

13 A. K. Tyagi, S. N. Achary and M. D. Mathews, J. Alloys Compd., 2002, 339, 207-210.

14 E. J. Liang, H. L. Huo, J. P. Wang and M. J. Chao, J. Phys. Chem. C, 2008, 112, 6577-6581.
15 N. Khosrovani, A. W. Sleight and T. Vogt, J. Solid State Chem., 1997, 132, 355-360.

16 Y. Yamamura, A. Horikoshi, S. Yasuzuka, H. Saitoh and K. Saito, Dalton Trans., 2011, 40, 2242-2248.

17 R. L. Withers, J. S. O. Evans, J. Hanson and A. W. Sleight, J. Solid State Chem., 1998, 137, 161-167.

18 U. L. C. Hemamala, F. El-Ghussein, D. V. S. Muthu, A. K. Krogh Andersen, S. Carlson, L. Ouyang and M. Kruger, Solid State Commun., 2007, 141, 680-684.

19 J. S. O. Evans, T. A. Mary and A. W. Sleight, J. Solid State Chem., 1997, 133, 580-583.

20 T. Hisashige, T. Yamaguchi, T. Tsuji and Y. Yamamura, J. Ceram. Soc. Jpn., 2006, 114, 607-611.

21 V. Korthuis, N. Khosrovani, A. W. Sleight, N. Roberts, R. Dupree and W. J. Warren, Chem. Mater., 1995, 7, 412-417.

22 E. Magni and G. A. Somorjai, J. Phys. Chem., 1996, 100, 14786-14793.

23 Y. C. Mao, W. Li, X. F. Sun, Y. J. Ma, J. Xia, Y. F. Zhao, X. H. Lu, J. Y. Gan, Z. Q. Liu, J. Chen, P. Liu and Y. X. Tong, CrystEngComm, 2012, 14, 1419-1424.

24 C. D. Wagner, Handbook of X-Ray photoelectron spectroscopy, ed. G. E. Muilenberg, Perkin-Elmer, 1979.

25 P. P. Sahoo, S. Sumithra, G. Madras and T. N. Guru Row, Inorg. Chem., 2011, 50, 8774-8781.

26 M. Maczka, W. Paraguassu, A. G. Souza Filho, P. T. C. Freire, J. Mendes Filho, F. E. A. Melo and J. Hanuza, J. Solid State Chem., 2004, 177, 2002-2006.

27 J. Z. Tao and A. W. Sleight, J. Solid State Chem., 2003, 173, 442-448. 